\title{
Evaluation of the therapeutic potentials of adipose Derived stem cells in comparison to hyaluronic acid in temporomandibular joint osteoarthritis A multi assessment study
}

\section{Original Article}

\author{
Maggie A Khairy, Inas A Abulmagd ${ }^{b}$ and Dina A Sabry \\ ${ }^{a}$ Department of Oral and Maxillofacial Surgery, Faculty of Dentistry, October 6 \\ University, ${ }^{b}$ Department of Oral and Maxillofacial Radiology, Faculty of Dentistry, \\ Al Fayoum University, ' Department of Medical Biochemistry and Molecular Biology, \\ Faculty of Medicine, Cairo University, Cairo, Egypt
}

\begin{abstract}
Objective: This study aims to assess the effectiveness of arthrocentesis followed by intraarticular injection of adipose derived stem cells versus hyaluronic acid in treatment of temporomandibular joint osteoarthritis and reversing the ongoing degenerative cascade. Evaluation was based on clinical radiographic and biochemical findings.

Materials and Methods: The study included thirty patients suffering from TMJ/OA. Clinical criteria and Computerized Tomography (CT scan) confirmed the diagnosis. Patients were divided into two equal groups; both groups underwent arthrocentesis pursued by hyaluronic acid injection for Group I, and chondrogenic differentiated adipose derived stem cells for Group II. Synovial fluid samples were collected preoperative and at the end of the study (18 months) to assess the TGF $\beta 1$ concentration. Clinical data (maximal mouth opening, lateral, protrusive movements, pain and joint sounds) were collected at 3, 6, 12 and 18 months. CT scans were repeated at 18 months.

Results: Group I showed initial improvement within clinical parameters but failed to sustain these results till the end of the study, no marked radiographic changes were noted. However, the TGF $\beta 1$ concentration showed significant decrease. Group II showed significant improvement within all parameters, Radiographic findings manifested remodeling of degenerative findings and TGF $\beta 1$ concentration was significantly decreased.

Conclusion: Adipose derived stem cell is an effective therapeutic treatment for TMJ/OA. It subsided all related clinical dysfunction and abates the ongoing degenerative cycle.
\end{abstract}

Key Words: Adipose derived stem cells, arthrocentesis, CT scan, hyaluronic acid, temporomandibular joint osteoarthritis.

Received: 14 March 2020, Accepted: 04 May 2020.

Corresponding Author: Maggie A Khairy, Department of Oral and Maxillofacial Surgery, Faculty of Dentistry October 6 University, Egypt, Tel.: +202264864, Mobile:+201060000949, E-mail: maggie_khairy@yahoo.com.

ISSN: 2090-097X, October 2019, Vol. 10, No. 4

\section{INTRODUCTION}

Temporomandibular Joint Osteoarthritis (TMJ /OA) is a progressive degenerative disease with concomitant inflammation ${ }^{[1]}$. It gradually advances giving rise to condylar cartilage degradation, cortical bone erosion, subcortical cysts, osteophytic changes, joint space narrowing and synovitis. Patients usually complain of impaired quality of life as they all suffer from tormenting pain, stiffness in the jaw with marked decrease in joint movements together with joint sounds mainly crepitations (grating sounds) which are sometimes allied by clicking $^{[2-3]}$.

Pathogenesis of TMJ/OA and factors triggering the degenerative cascade remains inconveniently studied. However, potential contributors for disease initiation include overloaded TMJ, internal derangements, muscle hyperactivity, aging, skeletal discrepancies together with genetic components ${ }^{[4-5]}$. It is worth mentioning that none of these theories proved to be the sole element responsible for initiation of the disorder.
Diagnosis of TMJ/OA is based on both clinical and radiological findings. Several radiographic techniques were advocated for $\mathrm{TMJ} / \mathrm{OA}$ radiographic assessment. However Computerized Tomograms (CT) proved to be of utmost benefit where bone degeneration is to be assessed .It is repeatedly proved that $\mathrm{CT}$ provides exquisite bone details with accurate detection of minimal degenerative changes together with its capability to provide very thin slices with high quality images in all three planes axial, sagittal, and coronal ${ }^{[6-7]}$.

Transforming growth factor $\beta 1$ (TGF $\beta 1$ ) is a cytokine which is present normally in the synovial fluid of all healthy joints. Never the less, its concentration increases up to three folds in osteoarthritic joints. Thus, TGF $\beta 1$ expression in $\mathrm{TMJ} / \mathrm{OA}$ can be of value in predicting the therapeutic outcome of different treatment modalities on the progression of the disease according to the severity of the degenerative process $^{[8-9]}$.

Considering that $\mathrm{TMJ} / \mathrm{OA}$ is a multifactorial condition with diverse clinical presentations made it a difficult 
challenge for only one therapeutic maneuver to completely resolve the disease. Multiple conservative treatment procedures were proposed including physical therapy, Pharmacological medications, intraoral appliances, and arthrocentesis which is either done solely or followed by intra articular injections ${ }^{[10-11]}$.

Arthrocentesis coupled with viscosupplementation proved efficient in relieving symptoms associated with $\mathrm{Tmj} /$ OA. Arthrocentesis was long advocated for its effectiveness on clearing the joint from all inflammatory mediators and cytokines aiming to regain intraarticular homeostasis ${ }^{[12]}$ as well as eliminating intraarticular effusion, reducing pain and minimizing loading effect on the joint which aids in preserving joint movements ${ }^{[13]}$.

Hyaluronic acid was advocated as a viscosupplement for $\mathrm{TMJ} / \mathrm{OA}$. It aids in preserving intraarticular homeostasis ,decreases inflammation, enhances lubrication within the joint thus reducing friction on joint cartilage in addition to its ability to stimulate production of innate hyaluronic $\operatorname{acid}^{[14]}$.

The recent past years showed uprising of the stem cellsbased therapy subsequent to their proven results in tissue engineering and regenerative medicine. Mesenchymal stem cells ,a subtype of the stem cells population have gained wide popularity due to their self-renewal capacity, multiple differentiation potentials, ease of isolation from various tissues including, bone marrow, muscles, dental pulp and fat cells (adipose tissue) ${ }^{[15-16]}$.

Gimble $^{[17]}$, in 2003 implied that stem cells utilized in regenerative medicine should meet several criteria including; abundancy, simple harvest technique, multilineage differentiation, can be effectively transplanted into the target site together with ease of differentiation technique. Practice proved that Adipose derived stem cells (ADSCs) fulfill these criteria in many aspects as they are abundant and easily accessible, their harvest technique is simple with minimal discomfort, limited donor site morbidity and less invasive that that of bone marrow aspiration. It is worth noting that researches proved that $1 \mathrm{gm}$ of adipose cells yields large quantities of stem cells in comparison to those obtained from the bone marrow aspiration $^{[18-19]}$. Moreover, ADSCs proved multipotent as they easily differentiate into various cell types e.g. chondrogenic, osteogenic, or myogenic cells under appropriate culture conditions ${ }^{[20]}$.

Adipose derived stem cells gained wide popularity as a therapeutic maneuver for TMJ osteoarthritis owing to their ability to restore tissue impairment by boosting native chondrocytes regeneration, eliciting an anti-inflammatory effect by decreasing levels of anti-inflammatory mediators within osteoarthritic joints and provide a stable environment within the joint to allow cartilage regeneration ${ }^{[21-23]}$.

\section{AIM OF THE STUDY}

The objective of our present study is to analyze the therapeutic efficacy of arthrocentesis followed by intraarticular injection of either hyaluronic acid or adipose derived stem cells as a definite treatment modality of TMJ /OA osteoarthritis. The evaluation includes clinical, radiological and biochemical findings.

\section{MATERIALS AND METHODS}

To apply all research goals, the researchers designed a single blind randomized controlled study. The study sample was allocated from the outpatient clinic, oral and maxillofacial department October 6 University. A total of thirty patients were enclosed in the study (26 females and four males) with age range 17 - 52 years old.

The study inclusion criteria followed the research diagnostic criteria for Temporomandibular joint disorders (RDC/TMDs axis I group III) which includes, pain in the Tmj area that increases during function, stiffness of the joint associated with limitation of all movements, crepitation which might be accompanied with clicking ${ }^{[24]}$. All patients selected suffered from bilateral TMJ osteoarthritis.

Clinical diagnosis was confirmed by computed tomography (CT scans). Patients exclusion criteria were, history of general arthritis or any other connective tissue disease, patients on anticoagulants, pregnancy or lactation, and patients who received any previous treatment for their present TMJ disorder.

All patients signed a written consent for both intended therapeutic maneuvers which were fully explained with details together with all possible related complications. Patients were assured of their right to withdraw from the study anytime they prefer to. Patients were randomly assigned to any of the two groups using sequentially numbered opaque sealed envelope (SNOSEs).

Group I: Patients received bilateral tmj intraarticular injection of $2 \mathrm{ml}$ of high molecular weight hyaluronic acid (Orthovisc)* into the superior joint space immediately subsequent to arthrocentesis using $200 \mathrm{ml}$ Ringer lactate for each side.

Group II: These patients had abdominal fat harvested for stem cells preparation. Temporomandibular arthrocentesis was performed using $200 \mathrm{ml}$ Ringer lactate solution. Right after the procedure $2 \mathrm{ml}$ of the prepared adipose derived stem cells were injected into the superior joint compartment of each joint.

Preoperative synovial fluid sample was collected from both groups prior to the arthrocentesis procedure . The second sample was retrieved at the end of the follow up period (18 months). Samples were sent for laboratory screening to assess the TGF $\beta 1$ concentration in both groups preoperative and by the end of the follow up period. 


\section{Collecting the Synovial Fluid Sample}

The procedure site was prepared aseptically then isolated and draped in the usual manner. The area was anesthetized by auriculotemporal nerve block using local anesthesia with vasoconstrictor. A wide bore needle (21 gauge) was inserted in the posterior part of upper joint space at a point $10 \mathrm{~mm}$ anterior to the tragus along the canthal tragal line. Two $\mathrm{ml}$ saline solution was injected into the upper joint space, then aspirated with the same syringe. The previous injection aspiration procedure was repeated for at least three times to obtain the synovial fluid sample. The obtained sample is collected in a tube and sent to the lab for synovial analysis and detection of TGF $\beta 1$ within the sample (Figure 1). The second synovial sample was collected by the same manner and sent for analysis at the end of the follow up period (18 months).

\section{Stem cells preparation}

\section{A. Harvest of abdominal Fats:}

The whole procedure was carried out under strict aseptic conditions. The patient was draped exposing the lower abdomen then the selected site was scrubbed using povidone iodine. The target area was injected subcutaneously by $15 \mathrm{cc}$ tumescent solution $(500 \mathrm{cc}$ ringer, $10 \mathrm{~cm}$ xylocaine and $1 \mathrm{ml}$ adrenaline). A resting period of 10 minutes is provided to allow for adequate fat emulsification

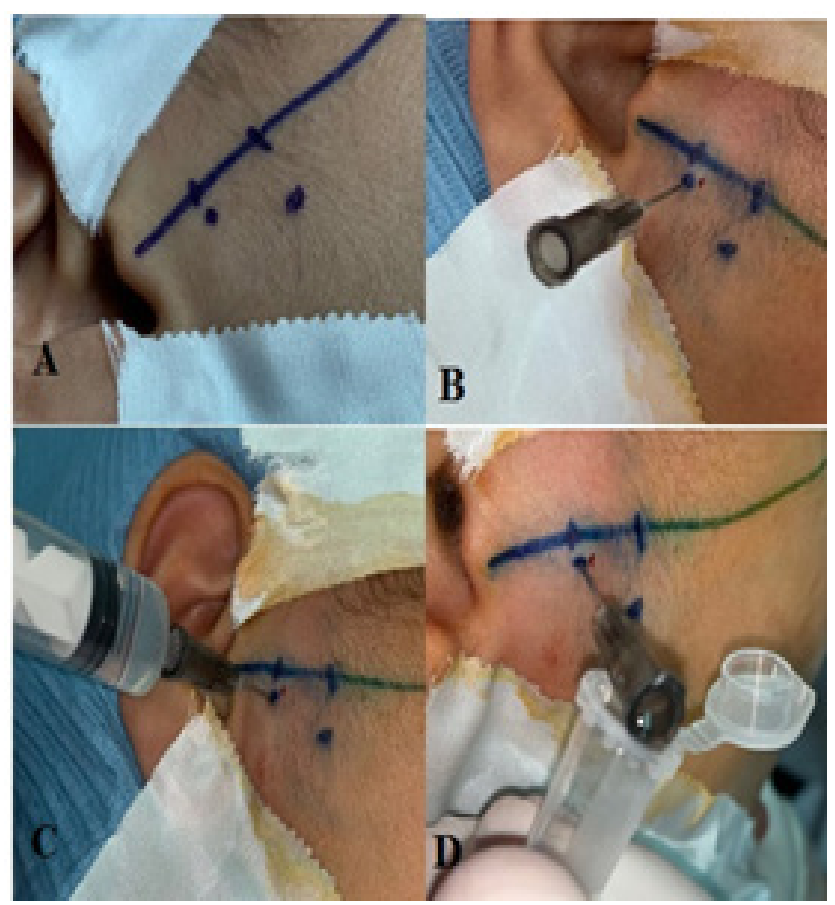

Figure 1: A. landmarks for needle insertion. B. Insertion of the needle C. Saline solution injectiomin superior joint space. D. Collectio of synovial fluid. followed by the liposuction procedure ${ }^{[25]}$. Liposuction is performed using cannula number four, which was inserted into the subcutaneous fat layer and moved to and fro in all directions. Negative pressure was maintained throughout the procedure to allow aspiration of 35-ml liquefied fats. Compressive dressing was applied to the donor site and the patient was prescribed analgesics for 48 hours and systemic antibiotics for 7 - 10 days (Figure 2)

\section{Cell culture and differentiation}

The collected lipoaspirate was processed according to the guidelines of Tomiyama, et al. ${ }^{[26]}$ for stem cells preparation. The procedure commenced with isolation and culture of fat cells present within the lipoaspirate, followed by enzymatic digestion using a mixture of collagenase II and Hank's Balanced Salt Solution (HBSS)*. The resultant emulsion was filtered and centrifuged, then added to a solution of DMEM (Dulbecco Modified Eagle Medium)** and $10 \%$ fetal bovine serum (Gibco/BRL) for 24 hours. All non-adherent cells were eradicated, while the attached cells were re-cultured in a mixture of DMEM media, fetal bovine serum (FBS), dual antibiotic solution (penicillinstreptomycin) together with amphotericin B (antifungal) to form large mature colonies. These colonies were trypsinized for 5 minutes at a temperature of $37^{\circ} \mathrm{C}$. The resultant cells were centrifuged then mixed with serumsupplemented media and incubated. These cultures were named first-passage cultures which were further expanded in vitro until passage three.

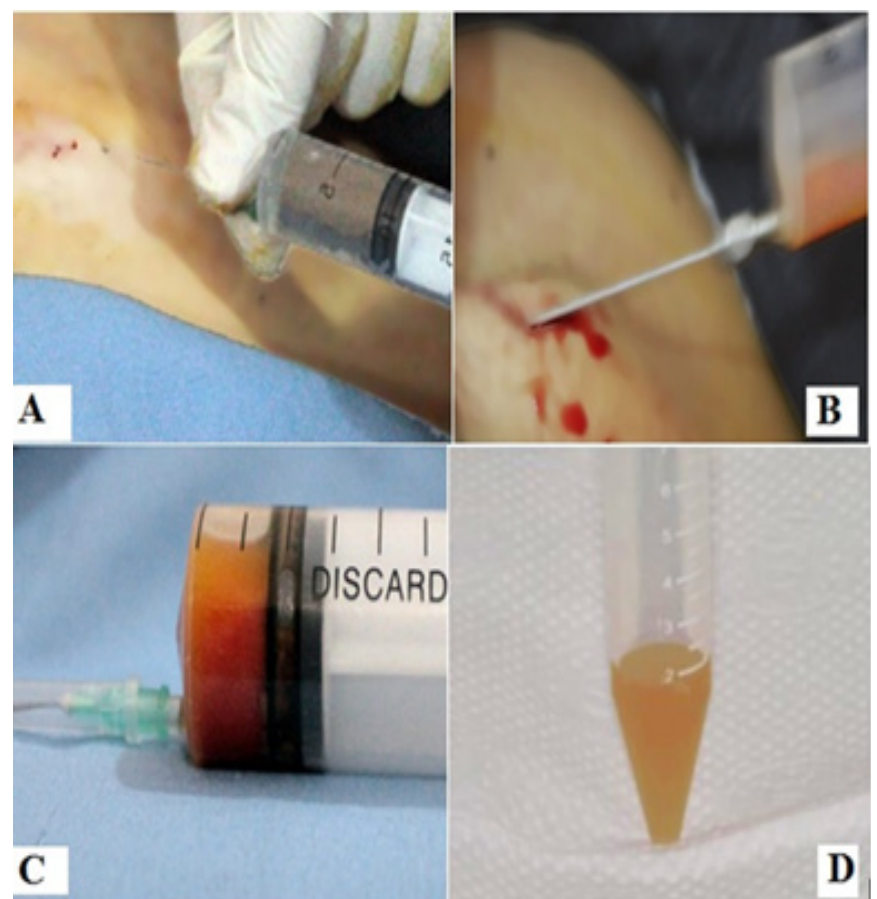

Figure 2: A. Injection oflocal anesthesia. B. liposuction of abdominal fat.

C. Collection of suitable amount of fat.

D. Delivery of differentiated stem cells ready for injection. 
After three consecutive passages the culture medium was changed to a chondrogenic differentiation medium, which consists of high glucose DMEM, bone morphogenic protein, TGF- $\beta 3$, dexamethasone, ascorbate 2-phosphate, proline, pyruvate and ITS + premix (Becton Dickinson: $6.25 \mu \mathrm{g} / \mathrm{ml}$ insulin, $6.25 \mu \mathrm{g} / \mathrm{ml}$ Transferrin, $6.25 \mathrm{ng} / \mathrm{ml}$ selenous acid, $1.25 \mathrm{mg} / \mathrm{ml}$ bovine serum albumin, $5.35 \mathrm{mg} /$ $\mathrm{ml}$ linoleic acid).

The medium was regularly replaced every 3 days for a total period of $21 \mathrm{~d}$ ays, and then the stem cells were ready to be used.

\section{Arthrocentesis Procedure}

The two-needle technique advocated by Nitzan, et al was followed, along with postulated landmarks ${ }^{[27]}$. Two Needles were inserted into the superior joint space acting as inlet and outlet during the procedure. Arthrocentesis of the joint was completed using $200 \mathrm{ml}$ of lactated ringer solution. It is worth mentioning that the outflow needle was periodically occluded in order to create hydraulic pressure within the joint space and patients were asked to open and close mouth and move it sideways to assure release of any present adhesions (Figure 3).

* Serva Electrophoresis GmbH, Mannheim.

**DMEM, Gibco/ BRL, Grand Island, New York, USA.

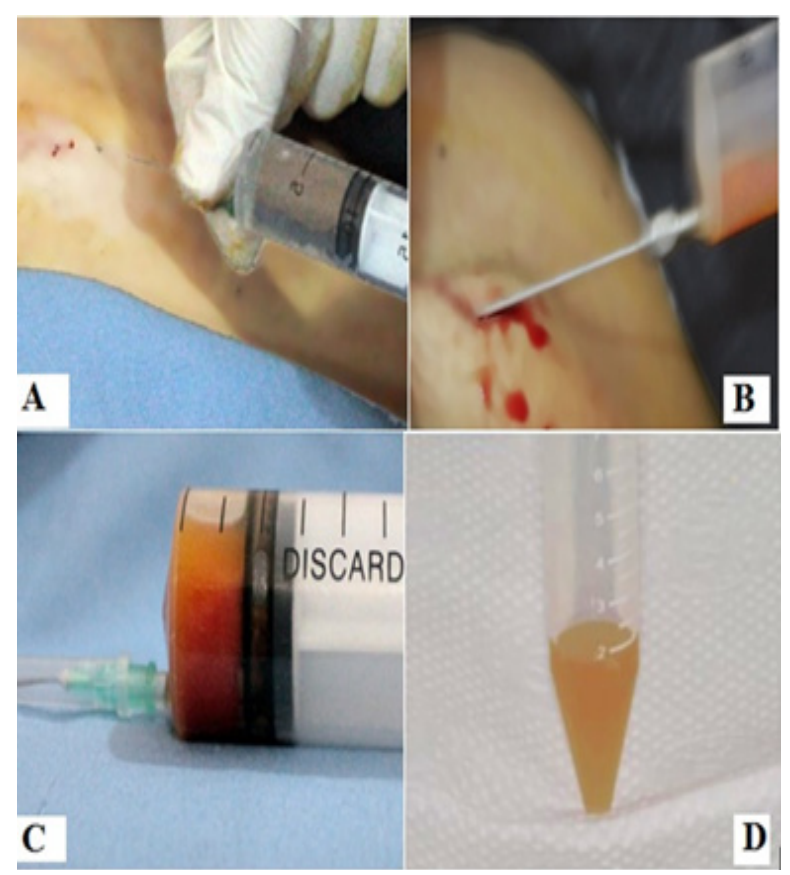

Figure 3: A injection oflocal anesthesi, Bliposuction of abdominal fat ominal fat, c collection of suitable amount of fat,Ddelivery of differentiated stem cells ready for injection.

At the end of the arthrocentesis procedure the outflow needle was removed and group I received $2 \mathrm{ml}$ of hyaluronic acid injection.
As for group II, $2 \mathrm{ml}$ of adipose derived stem cells were injected into the superior joint space (Figure 4).

All patients wore maxillary flat occlusal splints, 24 hours per day (except at meal times) for two weeks.

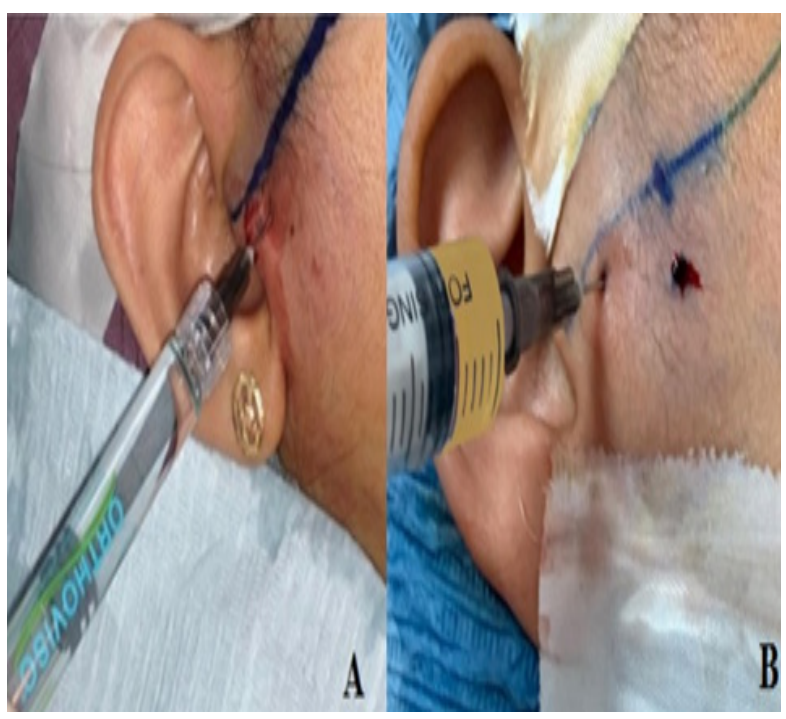

Figure 4: A. Group I injection of high molecular weight hyaluronic acid. B. Group II injection of chondrogenic differentiated Adipose Derived Stem Cells.

\section{Clinical data collected included were}

- Maximal interincisal opening by measuring the distance between the incisal edges of the upper and lower incisors using a caliper.

- Lateral and protrusive movements were measured using a caliper to assess the distance between the upper and lower midline in both lateral and forward movements consecutively.

- $\quad$ Pain according to visual analogue scale measured from 0 - 10.

- Joint sounds (Crepitation with or without clicking) were recorded by the patient and collected in a chart on daily basis.

All data were collected preoperative and postoperative according to the following timings: $1,3,6,12$ and 18 months.

Bilateral joint CT scans were done preoperative and at 18 months postoperative. The scans were carried out on Siemens SOMATOM Emotion Spiral Single Slice Scanner at $120 \mathrm{KVp}$ and $200 \mathrm{~mA}$ settings with acquisition time of $1 \mathrm{~s}$. CT scanning was carried out in direct axial sections while the coronal and sagittal planes were reconstructed with approximate slice thickness of $2 \mathrm{~mm}$ using bone window. All CT scan images (preoperative and postoperative) were recorded and interpreted by a qualified radiologist who was blinded to the identity of the patient and the treatment maneuver. 
DICM datasets of both scans were imported into a thirdparty software package (Ondemand 3D Dental (Cybermed, South Korea), where both data sets fused to align both scans at the same orientation, hence reconstructed planes would be identical at both datasets. Fusion aligns both datasets depending on similarity of anatomical landmarks at both datasets. After fusion was made using auto register tool at the software, both datasets were ready to navigate through simultaneously. Certain Coronal and sagittal cuts were reconstructed for each patient to emphasize the changes in the condylar head and articular space.

\section{Analysis of Statistical data}

Quantitative evidence provided was studied for normality by reviewing the distribution of data and utilizing tests of normality (Kolmogorov-Smirnov and Shapiro-Wilk tests). Data collected included age, maximal mouth opening, lateral excursions, protrusive movements and the concentration level of TGF- $\beta 1$ demonstrated normal (parametric) distribution. In contrast both pain and joint sounds attained non-normal (nonparametric) distribution. Parametric data were reported in the form of mean, standard deviation (SD) and $95 \%$ Confidence Interval $(95 \% \mathrm{CI})$ values.

On the other hand, Non-parametric data were presented as median and range values. Concerning parametric data analysis, the Student's t-test was analyzed to compare between mean age values within both groups. As for Repeated sequential values gained including interincisal, lateral and protrusive measurements together with the TGF- $\beta 1$ concentration, ANOVA tests were performed. The test provides comparative mean analysis between the two groups as well as displaying the effect of time on the data collected within each group. It is worth mentioning that if the ANOVA test results were significant, it was followed by the Bonferroni's post-hoc test for pair-wise comparisons. As for non-parametric data, comparative analysis between results of the two groups was done using the Mann-Whitney U test. In regard to changes by time taking place in each group, data collected were assessed using Friedman's test, while Dunn's test was used for pairwise comparisons. Qualitative data were conferred in the form of frequencies and percentages using Fisher's Exact test to carry out comparisons between the groups. The significance level was set at $P \leq 0.05$. Statistical analysis accomplished using IBM SPSS Statistics for Windows, Version 23.0. Armonk, NY: IBM Corp.

\section{RESULTS}

\section{Demographic data}

Results obtained from the present study showed no significant difference between age values or gender distribution in the two groups (Table 1).

Table 1: Assessment of mean age and gender within the two groups

\begin{tabular}{lccc}
\hline & $\begin{array}{c}\text { Group I } \\
(\mathrm{n}=15)\end{array}$ & $\begin{array}{l}\text { Group II } \\
(\mathrm{n}=15)\end{array}$ & $P$-value \\
\hline Age (years) & & & \\
Mean (SD) & $34.5(9.6)$ & $37(8.8)$ & 0.459 \\
Gender [n (\%)] & & & \\
Male & $3(20)$ & $2(13.3)$ & 1.000 \\
Female & $12(80)$ & $13(86.7)$ & \\
*: Significant at $P \leq 0.05$. & &
\end{tabular}

\section{Maximal interincisal opening (MIO)}

Maximal interincisal opening results presented no significant difference amidst the two groups pre-operatively, at 1 month as well as 3 months. However, at 6, 12 and 18 months Group I showed statistically significant lower maximum inter-incisal opening than Group II (Table 2).

As for inter group results, Group I manifested statistically significant increase in maximum inter-incisal opening by time at 1 month as well as 3 months. On the contrary, results collected at 6,12 and 18 months postoperative presented a notable decrease in mean maximum interincisal opening. Despite this decrease results gained at 18 months still showed a higher mean value in comparison to the pre-operative measurements.

Similarly, Group II showed a statistically significant increase in maximum inter-incisal opening at 1,3 as well as 6 months postoperative. However no significant changes were noted at 6,12 and 18 months. Results obtained from the two groups at 18 months postoperative were significantly higher than the preoperative results (Figure 5).

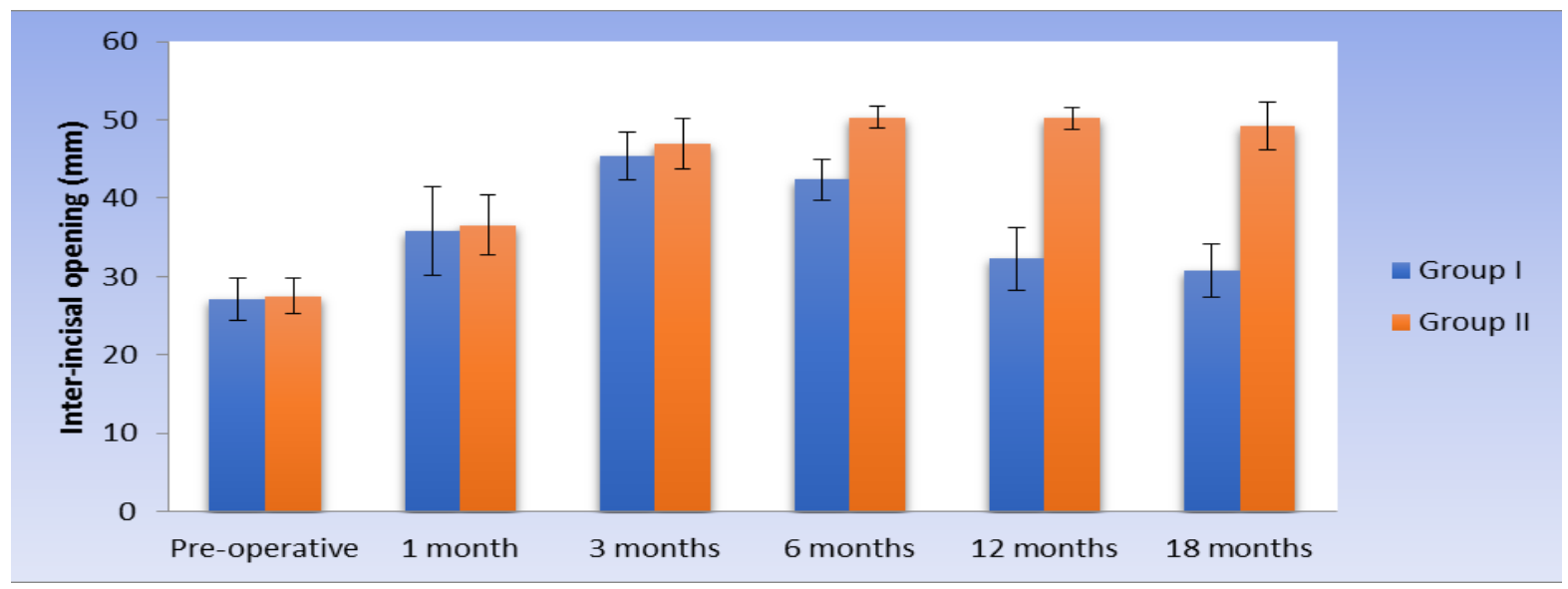

Figure 5: Bar chart: demonstrating values of mean and standard deviation for MIO in the two group 
Table 2: Statistical analysis and results of repeated variables ANOVA test (comparing maximal inter-incisal opening in the two groups and changes by time within each group)

\begin{tabular}{|c|c|c|c|c|}
\hline Time & Group I $(\mathrm{n}=15)$ & Group II $(\mathrm{n}=15)$ & $P$-value & Effect size (Partial Eta Squared) \\
\hline \multicolumn{5}{|l|}{ Pre-operative } \\
\hline Mean (SD) & $27.1(2.7)^{\mathrm{F}}$ & $27.5(2.3)^{\mathrm{D}}$ & \multirow{2}{*}{0.619} & \multirow{2}{*}{0.009} \\
\hline $95 \% \mathrm{CI}$ & $25.6-28.6$ & $26.2-28.8$ & & \\
\hline \multicolumn{5}{|l|}{1 month } \\
\hline Mean (SD) & $35.8(5.6)^{\mathrm{C}}$ & $36.6(3.9)^{\mathrm{C}}$ & \multirow{2}{*}{0.652} & \multirow{2}{*}{0.007} \\
\hline $95 \% \mathrm{CI}$ & $32.7-38.9$ & $34.4-38.8$ & & \\
\hline \multicolumn{5}{|l|}{3 months } \\
\hline Mean (SD) & $45.4(3)^{\mathrm{A}}$ & $47(3.2)^{\mathrm{B}}$ & \multirow{2}{*}{0.170} & \multirow{2}{*}{0.066} \\
\hline $95 \% \mathrm{CI}$ & $43.7-47.1$ & $45.2-48.8$ & & \\
\hline \multicolumn{5}{|l|}{6 months } \\
\hline Mean (SD) & $42.4(2.6)^{\mathrm{B}}$ & $50.3(1.4)^{\mathrm{A}}$ & \multirow{2}{*}{$<0.001 *$} & \multirow{2}{*}{0.791} \\
\hline $95 \% \mathrm{CI}$ & $41-43.8$ & $49.5-51$ & & \\
\hline \multicolumn{5}{|l|}{12 months } \\
\hline Mean (SD) & $32.3(4)^{\mathrm{D}}$ & $50.2(1.4)^{\mathrm{A}}$ & \multirow{2}{*}{$<0.001 *$} & \multirow{2}{*}{0.907} \\
\hline $95 \% \mathrm{CI}$ & $30.1-34.5$ & $49.4-51$ & & \\
\hline \multicolumn{5}{|l|}{18 months } \\
\hline Mean (SD) & $30.7(3.4)^{\mathrm{E}}$ & $49.2(3.1)^{\mathrm{A}}$ & \multirow{2}{*}{$<0.001 *$} & \multirow{2}{*}{0.897} \\
\hline $95 \% \mathrm{CI}$ & $28.8-32.5$ & $47.5-50.9$ & & \\
\hline$P$-value (Changes by time) & $<0.001 *$ & $<0.001^{*}$ & & \\
\hline Effect size (Partial Eta Squared) & 0.933 & 0.970 & & \\
\hline
\end{tabular}

* Significant at $P \leq 0.05$, Different superscripts in the same column signifies statistically significant alterations by time.

\section{Lateral Excursion}

Regarding lateral excursions measurements no statistical differences were noted between the two groups pre-operatively, at 1, 3 and 6 months. Meanwhile, at 12- and 18-months postoperative group I showed statistically lower lateral excursion than Group II (Table 3).

As for change by time within each group, Group I demonstrated a significant increase at 1 and 3 months respectively and sustained with no considerable change till 6 months postoperative. Nonetheless, a statistically significant decrease was evident at 12 and 18 months postoperative.

Concerning Group II, a statistically significant increase was marked at 1 and 3 months postoperative while at 6, 12 and 18 months, there were no attained change in mean lateral excursion scores. It is worth noting that both groups showed a statistically significant higher value at the end of the follow up period compared to the pre-operative measurements (Figure 6).

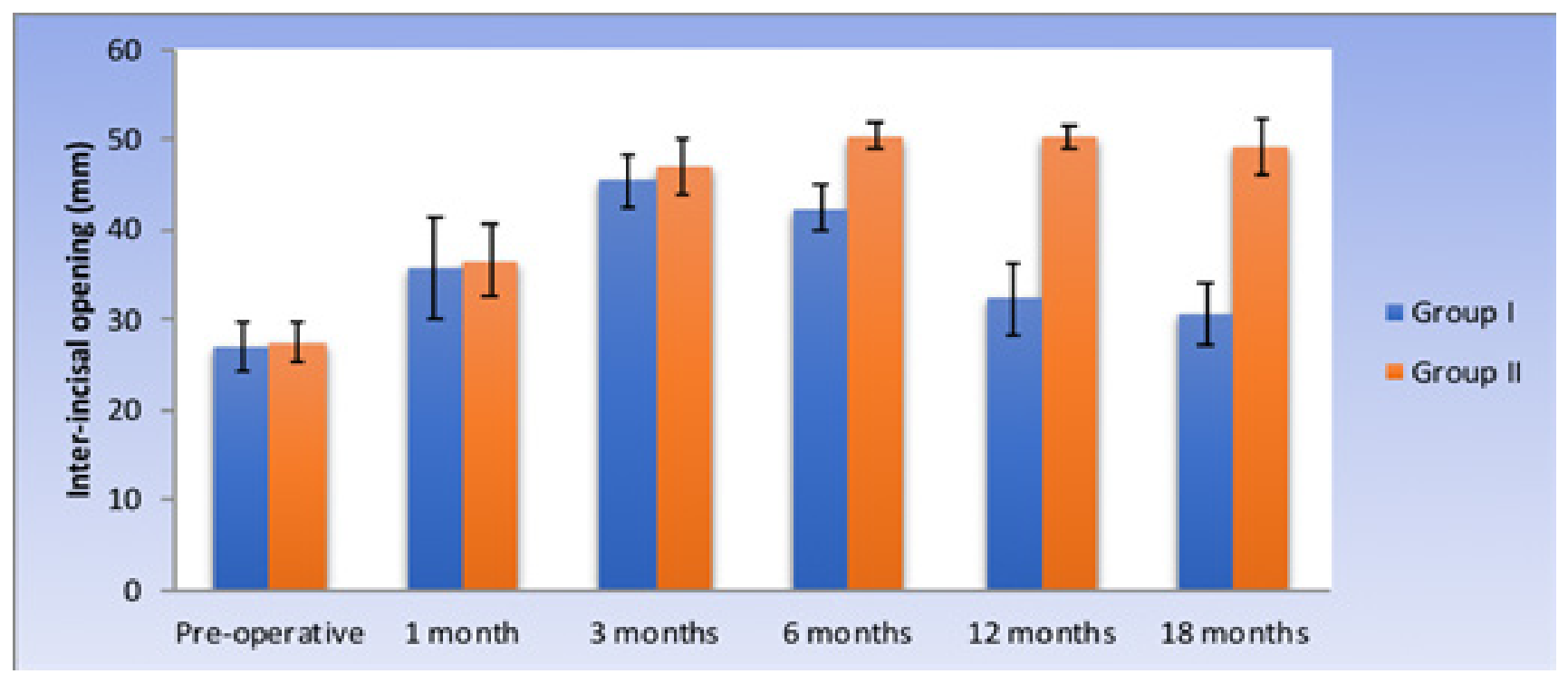

Figure 6: Bar chart representing mean and standard deviation values for lateral excursion measurements in the two groups. 
Table 3: Comparing lateral excursion measurements in the two groups and changes by time within each group (ANOVA test)

\begin{tabular}{|c|c|c|c|c|}
\hline Time & Group I $(\mathrm{n}=15)$ & Group II $(\mathrm{n}=15)$ & $P$-value & Effect size (Partial Eta Squared) \\
\hline \multicolumn{5}{|l|}{ Pre-operative } \\
\hline Mean (SD) & $2.1(0.8)^{\mathrm{E}}$ & $2.4(0.9)^{\mathrm{C}}$ & \multirow{2}{*}{0.493} & \multirow{2}{*}{0.023} \\
\hline $95 \% \mathrm{CI}$ & $1.5-2.7$ & $1.7-3$ & & \\
\hline \multicolumn{5}{|l|}{1 month } \\
\hline Mean (SD) & $6.3(1.5)^{\text {в }}$ & $5.5(1.5)^{\text {в }}$ & \multirow{2}{*}{0.217} & \multirow{2}{*}{0.072} \\
\hline $95 \% \mathrm{CI}$ & $5.3-7.2$ & $4.4-6.5$ & & \\
\hline \multicolumn{5}{|l|}{3 months } \\
\hline Mean (SD) & $8.4(0.8)^{\mathrm{A}}$ & $8.4(0.7)^{\mathrm{A}}$ & \multirow{2}{*}{0.865} & \multirow{2}{*}{0.001} \\
\hline $95 \% \mathrm{CI}$ & $7.9-8.9$ & $7.9-8.8$ & & \\
\hline \multicolumn{5}{|l|}{6 months } \\
\hline Mean (SD) & $8.4(0.8)^{\mathrm{A}}$ & $8.4(0.7)^{\mathrm{A}}$ & \multirow{2}{*}{0.865} & \multirow{2}{*}{0.001} \\
\hline $95 \% \mathrm{CI}$ & $7.9-8.9$ & $7.9-8.8$ & & \\
\hline \multicolumn{5}{|l|}{12 months } \\
\hline Mean (SD) & $4.4(1)^{\mathrm{C}}$ & $8.4(0.7)^{\mathrm{A}}$ & \multirow{2}{*}{$<0.001^{*}$} & \multirow{2}{*}{0.853} \\
\hline $95 \% \mathrm{CI}$ & $3.7-5$ & $7.9-8.8$ & & \\
\hline \multicolumn{5}{|l|}{18 months } \\
\hline Mean (SD) & $3.5(0.7)^{\mathrm{D}}$ & $8.3(0.9)^{\mathrm{A}}$ & \multirow{2}{*}{$<0.001 *$} & \multirow{2}{*}{0.921} \\
\hline $95 \% \mathrm{CI}$ & $3.1-3.9$ & $7.7-8.8$ & & \\
\hline$P$-value (Changes by time) & $<0.001^{*}$ & $<0.001^{*}$ & & \\
\hline Effect size (Partial Eta Squared) & 0.971 & 0.945 & & \\
\hline
\end{tabular}

*: Significant at $P \leq 0.05$, Different superscripts in the same column indicate statistically significant changes by time.

\section{Protrusive movement}

Protrusive movement results revealed no significant difference between the two groups in the preoperative measurements as well as 1, 3 and 6 months. However, at 12 and 18 months postoperative Group I showed statistically significantly lower mean protrusive movement than Group II (Table 4).

Pertaining changes of protrusive measurements by time within each group revealed a statistically significant increase in Group I at 1 and 3 months postoperative. However, at 6,12 and 18 months postoperative a statistically significant decrease was noted. As for Group II, data collected emphasized a statistically significant increase in protrusive movement at 1 month postoperative in contrast to $3,6,12$ and 18 months measurements which showed no statistically significant change (Figure 7). It is worth mentioning that readings at 18 months postoperative within the two groups manifested a statistically significant higher mean value compared with the pre-operative measurements.

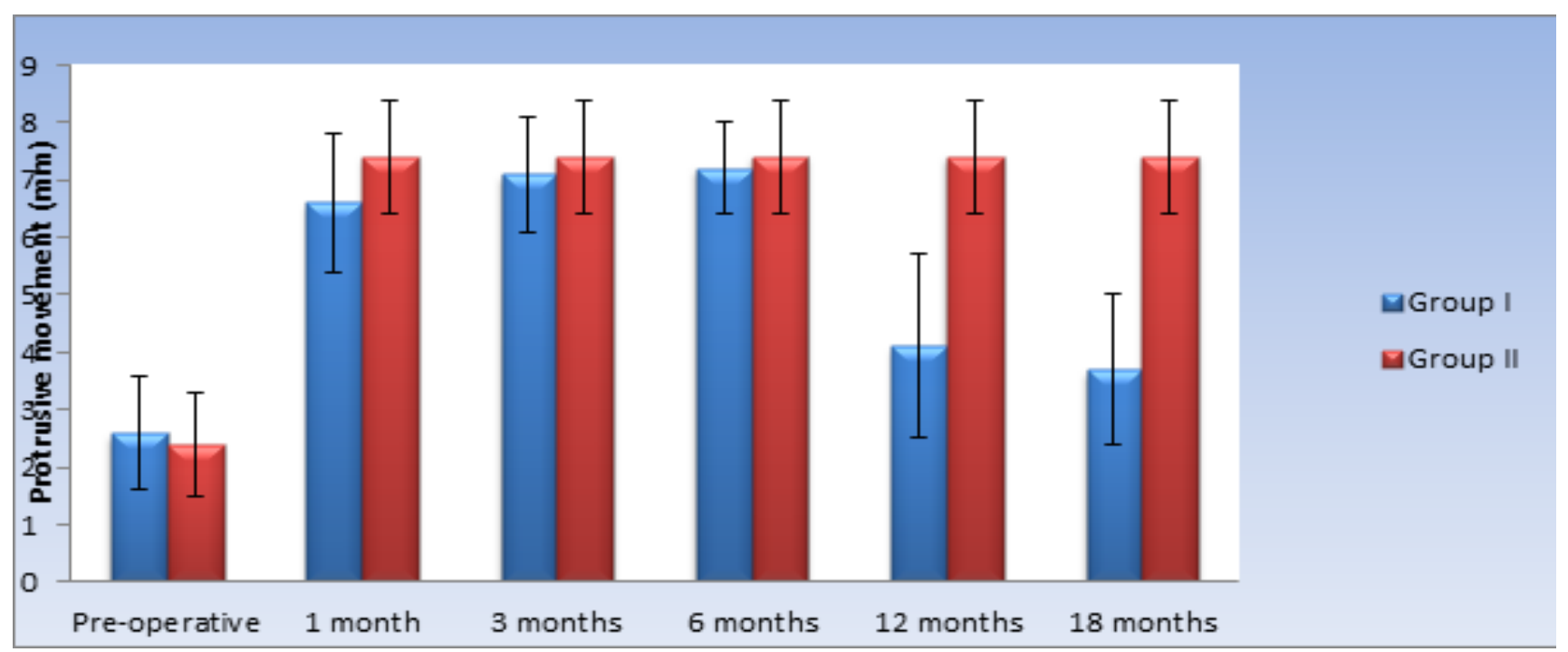

Figure 7: Bar chart representing mean and standard deviation values for protrusive movement measurements in the two groups. 
Table 4: Descriptive statistics and results of repeated measures ANOVA test for comparison between protrusive movement in the two groups as well as the changes by time within each group

\begin{tabular}{|c|c|c|c|c|}
\hline Time & Group I $(n=15)$ & Group II $(n=15)$ & $P$-value & Effect size (Partial Eta Squared) \\
\hline \multicolumn{5}{|l|}{ Pre-operative } \\
\hline Mean (SD) & $2.6(1)^{\mathrm{D}}$ & $2.4(0.9)^{\mathrm{B}}$ & \multirow{2}{*}{0.676} & \multirow{2}{*}{0.009} \\
\hline $95 \% \mathrm{CI}$ & $1.8-3.4$ & $1.6-3.2$ & & \\
\hline \multicolumn{5}{|l|}{1 month } \\
\hline Mean (SD) & $6.6(1.2)^{\mathrm{A}}$ & $7.4(1)^{\mathrm{A}}$ & \multirow{2}{*}{0.128} & \multirow{2}{*}{0.117} \\
\hline $95 \%$ CI & $5.9-7.3$ & $6.7-8.1$ & & \\
\hline \multicolumn{5}{|l|}{3 months } \\
\hline Mean (SD) & $7.1(1)^{\mathrm{A}}$ & $7.4(1)^{\mathrm{A}}$ & \multirow{2}{*}{0.558} & \multirow{2}{*}{0.018} \\
\hline $95 \% \mathrm{CI}$ & $6.4-7.8$ & $6.7-8$ & & \\
\hline \multicolumn{5}{|l|}{6 months } \\
\hline Mean (SD) & $7.2(0.8)^{\mathrm{A}}$ & $7.4(1)^{\mathrm{A}}$ & \multirow{2}{*}{0.689} & \multirow{2}{*}{0.009} \\
\hline $95 \% \mathrm{CI}$ & $6.6-7.8$ & $6.8-7.9$ & & \\
\hline \multicolumn{5}{|l|}{12 months } \\
\hline Mean (SD) & $4.1(1.6)^{\mathrm{B}}$ & $7.4(1)^{\mathrm{A}}$ & \multirow{2}{*}{$<0.001^{*}$} & \multirow{2}{*}{0.625} \\
\hline $95 \% \mathrm{CI}$ & $3.2-5$ & $6.5-8.2$ & & \\
\hline \multicolumn{5}{|l|}{18 months } \\
\hline Mean (SD) & $3.7(1.3)^{\mathrm{C}}$ & $7.4(1)^{\mathrm{A}}$ & \multirow{2}{*}{$<0.001^{*}$} & \multirow{2}{*}{0.844} \\
\hline $95 \% \mathrm{CI}$ & $3-4.4$ & $6.5-8.2$ & & \\
\hline$P$-value (Changes by time) & $<0.001^{*}$ & $<0.001^{*}$ & & \\
\hline Effect size (Partial Eta Squared) & 0.907 & 0.927 & & \\
\hline
\end{tabular}

*: Significant at $P \leq 0.05$, Different superscripts in the same column indicate statistically significant changes by time.

\section{Pain Scores (visual analogue scale)}

Pain scores manifested no statistically significant differences between the two groups preoperatively, after 1 month as well as 3 months respectively. However, Group I results exhibited statistically significant higher median pain scores than those of Group II after 6,12 as well as 18 months (Table 5).
Referring to changes by time in Group I, there was a statistically significant decrease in median pain scores at 1 month as well as 3 months. Oppositely, results obtained at 6,12 and 18 months, presented a statistically significant increase in median pain scores. Despite this increase, still median pain scores at 18 months showed statistically significantly lower value than pre-operative pain scores (Figure 8).

Table 5: Mann-Whitney U test comparing pain scores in the two groups and Friedman's test evaluating the changes by time within each group

\begin{tabular}{|c|c|c|c|c|c|c|}
\hline \multirow{2}{*}{ Time } & \multicolumn{2}{|c|}{ Group I $(\mathrm{n}=15)$} & \multicolumn{2}{|c|}{ Group II (n = 15) } & \multirow{2}{*}{$P$-value } & \multirow{2}{*}{ Effect size $(d)$} \\
\hline & Median & Range & Median & Range & & \\
\hline Pre-operative & $10^{\mathrm{A}}$ & $6-10$ & $10^{\mathrm{A}}$ & $6-10$ & 1.000 & 0.000 \\
\hline 1 month & $7^{\text {в }}$ & $4-9$ & $7^{\text {в }}$ & $4-9$ & 0.187 & 0.467 \\
\hline 3 months & $2^{\mathrm{D}}$ & $0-4$ & $2^{\mathrm{C}}$ & $0-3$ & 0.369 & 0.322 \\
\hline 6 months & $2^{\mathrm{D}}$ & $0-5$ & $0^{\mathrm{D}}$ & $0-2$ & $0.001^{*}$ & 1.464 \\
\hline 12 months & $5^{\mathrm{C}}$ & $3-6$ & $0^{\mathrm{D}}$ & $0-2$ & $<0.001^{*}$ & 3.254 \\
\hline 18 months & $9^{\mathrm{A}}$ & $4-10$ & $0^{\mathrm{D}}$ & $0-2$ & $<0.001 *$ & 3.254 \\
\hline$P$-value (Changes by time) & $<0.001 *$ & & $<0.001^{*}$ & & & \\
\hline Effect size (w) & 0.858 & & 0.879 & & & \\
\hline
\end{tabular}

*: Significant at $P \leq 0.05$, Different superscripts in the same column indicate statistically significant changes by time. 


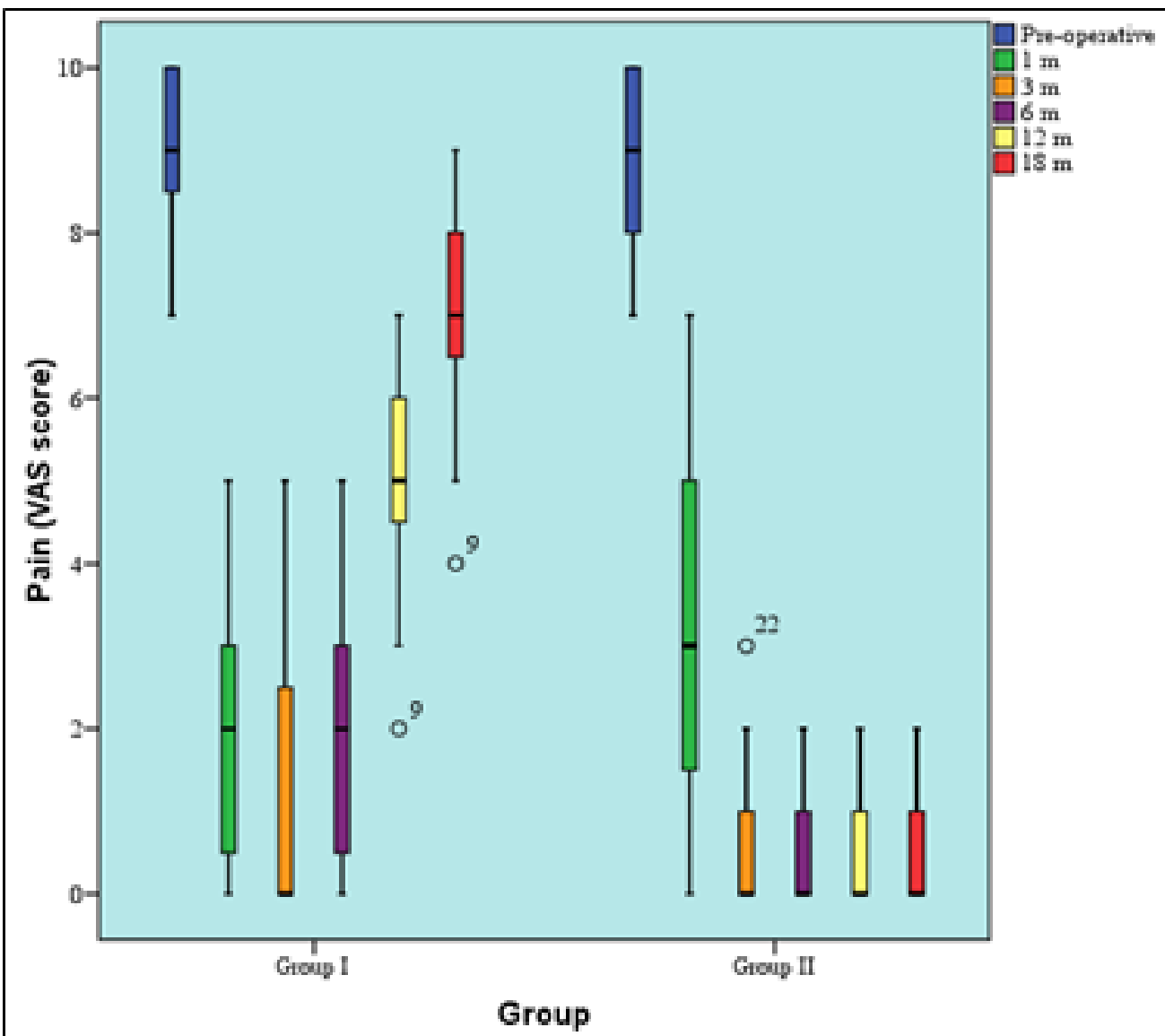

Figure 8: Box plot showing median and range values for pain scores in the two groups (Circles represent outliers).

\section{Joint sounds (VAS) scores}

Joint sounds scores revealed no statistically significant difference between the two groups preoperatively, after 1 month as well as 3 months. It is worth mentioning that Group I showed statistically significantly higher median joint sounds scores than Group II at 6,12 as well as 18 months respectively (Table 6).

Regarding changes by time in Group I, a statistically significant decrease in median joint sounds scores was shown at 1 and 3 months. In contrast, results obtained at 6,12 as well as 18 months expressed a statistically significant increase in median joint sounds scores. The median joint sounds score after 18 months showed nonstatistically significant difference from pre-operative joint sounds score.

On the other hand, Group II, showed a statistically significant decrease in median joint sounds scores at 1,3 as well as 6 months. However, no statistically significant change was noted at 12 or 18 months postoperative (Figure 9).

Table 6: -Mann-Whitney U test comparing joint sounds scores in the two groups and Friedman's test for the changes by time within each group

\begin{tabular}{ccccccc}
\hline \multirow{2}{*}{ Time } & \multicolumn{2}{c}{ Group I $(\mathrm{n}=15)$} & \multicolumn{2}{c}{ Group II $(\mathrm{n}=15)$} & \multirow{2}{*}{$P$-value } & Effect size (d) \\
\cline { 2 - 4 } & Median & Range & Median & Range & & 0.206 \\
\hline Pre-operative & $9^{\mathrm{A}}$ & $7-10$ & $9^{\mathrm{A}}$ & $7-10$ & 0.557 & 0.636 \\
1 month & $2^{\mathrm{D}}$ & $0-5$ & $3^{\mathrm{B}}$ & $0-7$ & 0.093 & 0.330 \\
3 months & $0^{\mathrm{E}}$ & $0-5$ & $0^{\mathrm{C}}$ & $0-3$ & 0.322 & 1.020 \\
6 months & $2^{\mathrm{D}}$ & $0-5$ & $0^{\mathrm{C}}$ & $0-2$ & $0.009^{*}$ & 3.152 \\
12 months & $5^{\mathrm{C}}$ & $2-7$ & $0^{\mathrm{C}}$ & $0-2$ & $<0.001^{*}$ & 3.254 \\
\hline 18 months & $7^{\mathrm{B}}$ & $4-9$ & $0^{\mathrm{C}}$ & $0-2$ & $<0.001^{*}$ & \\
\hline$P$-value (Changes by time) & $<0.001^{*}$ & $<0.001^{*}$ \\
\hline Effect size (w) & 0.952 & 0.807 & \\
\hline
\end{tabular}

*: Significant at $P \leq 0.05$, Different superscripts in the same column indicate statistically significant changes by tim 


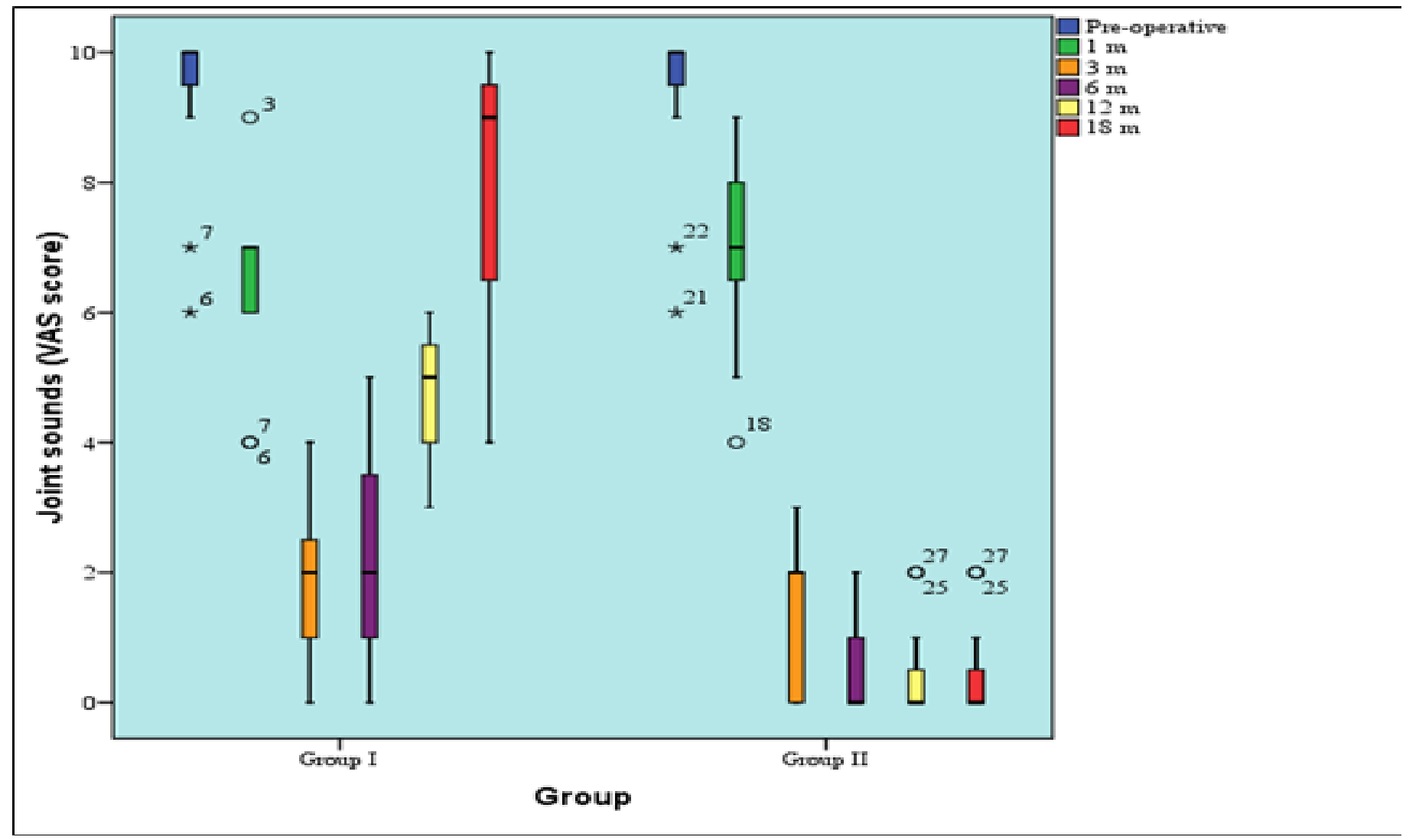

Figure 9: Box plot showing median and range values for joint sounds scores within the two groups (Stars and circles represent outliers).

\section{TGF-p1 level}

Pre-operatively, TGF- $\beta 1$ concentration within the synovial fluid showed no statistically significant difference between the two groups (Table 7). On the other hand, Group I showed statistically significant higher mean TGF- $\beta 1$ concentration than Group II. Yet, at 18 months both groups showed statistically significant decrease in TGF- $\beta 1$ level in comparison to the pre-operative level (Figure 10).

\section{Radiographic Results}

Preoperative CT scans for patients of both groups showed bilateral osteoarthritic changes including condylar flattening or erosion, osteophytes, narrowing of joint space and bone sclerosis.

However, by the end of the 18 months postoperative assessment Group I showed nearly no changes of the osteoarthritic findings, except for three patients who showed widening of the joint space (Figures 11 and 12).

As for group II all patients showed remarkable evidence of bony regeneration manifested as restoration of condylar contour to nearly normal shape, formation of new bone, dissolution of osteophytes, decrease sclerosis and widening of joint space (Figure 13 and 14).

Table 7: Descriptive statistics and results of repeated measures ANOVA test for comparison between TGF- $\beta 1$ levels in the two groups as well as the changes by time within each group

\begin{tabular}{|c|c|c|c|c|}
\hline Time & Group I $(\mathrm{n}=15)$ & Group II $(\mathrm{n}=15)$ & $P$-value & Effect size (Partial Eta Squared) \\
\hline \multicolumn{5}{|l|}{ Pre-operative } \\
\hline Mean (SD) & $471.6(39.1)$ & $453.9(47.6)$ & \multirow{2}{*}{0.274} & \multirow{2}{*}{0.043} \\
\hline $95 \%$ CI & $449.9-493.3$ & $427.5-480.2$ & & \\
\hline \multicolumn{5}{|l|}{ Post-operative } \\
\hline Mean (SD) & $343.7(107.7)$ & $135.7(18.4)$ & \multirow{2}{*}{$<0.001^{*}$} & \multirow{2}{*}{0.660} \\
\hline $95 \% \mathrm{CI}$ & $284.1-403.4$ & $125.5-145.9$ & & \\
\hline$P$-value (Changes by time) & $<0.001^{*}$ & $<0.001 *$ & & \\
\hline Effect size (Partial Eta Squared) & 0.559 & 0.887 & & \\
\hline
\end{tabular}




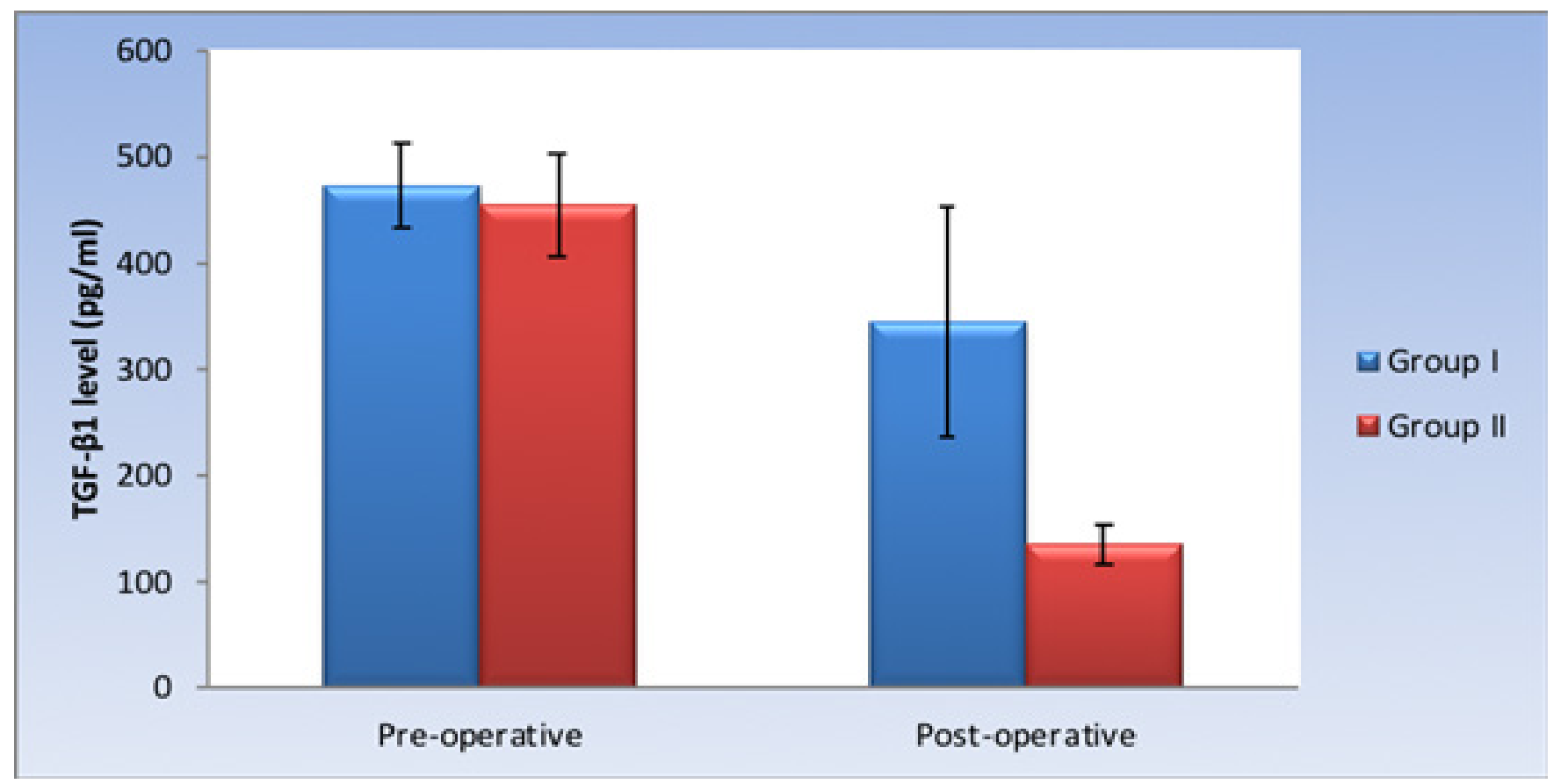

Figure 10: Bar chart representing mean and standard deviation values for TGF- $\beta 1$ levels in the two groups.

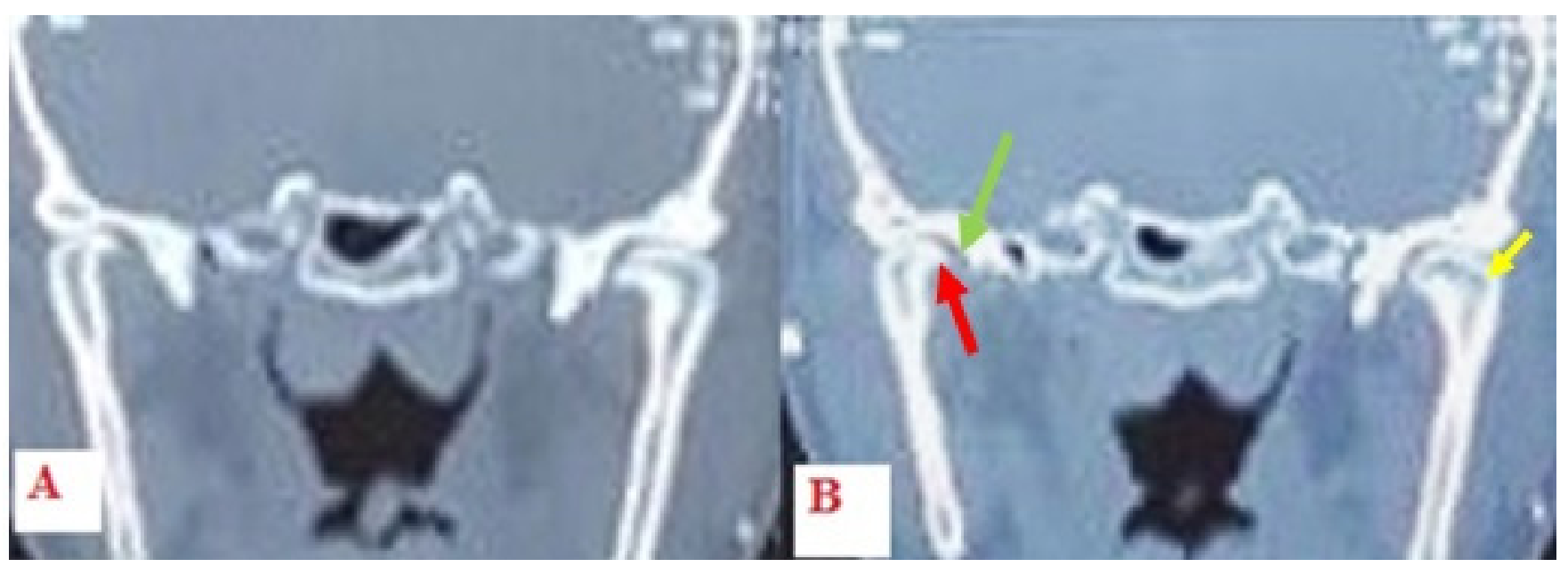

Figure 11: Group I CT (coronal view) A) preoperative CT showing narrowing of joint space (green arrow) osteophytes (red arrow) and erosion of condyles (yellow arrow) Postoperative. B) Postoperative CT showing very mild reparative changes.

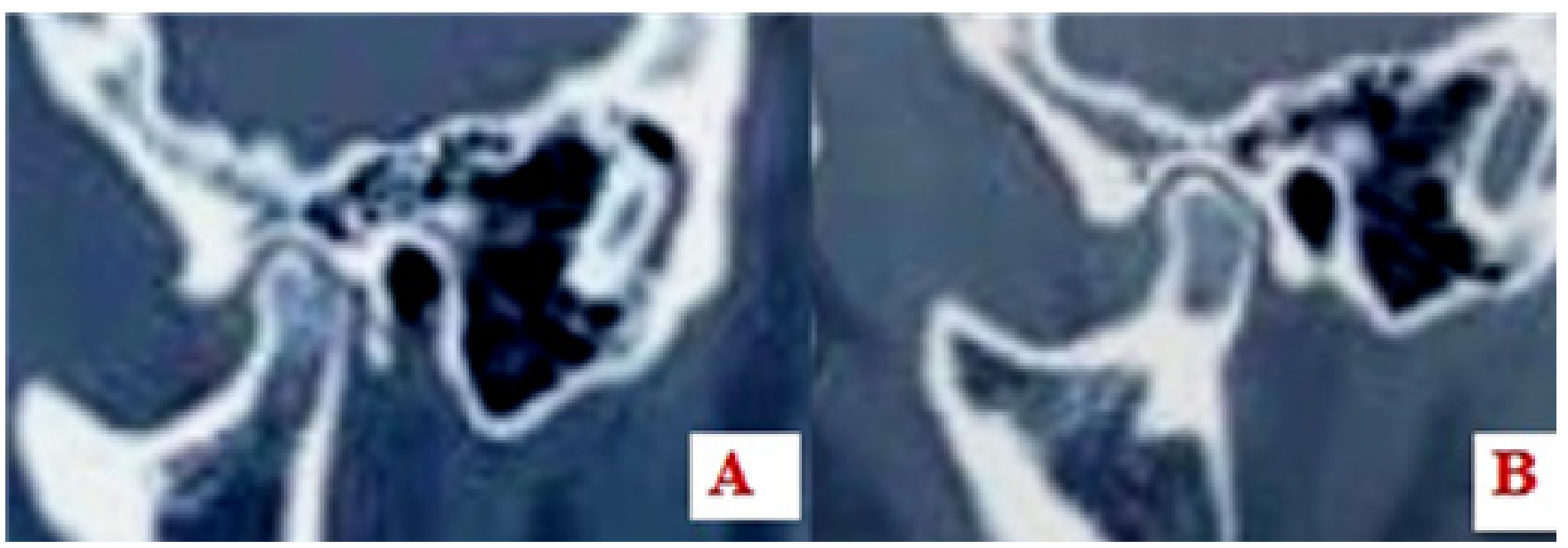

Figure 12: Group I CT (sagittal view) A: Preoperative CT showing narrowing of joint space, erosions of condyle B Postoperative CT showing slight increase in joint space and reparative changes of erosions. 


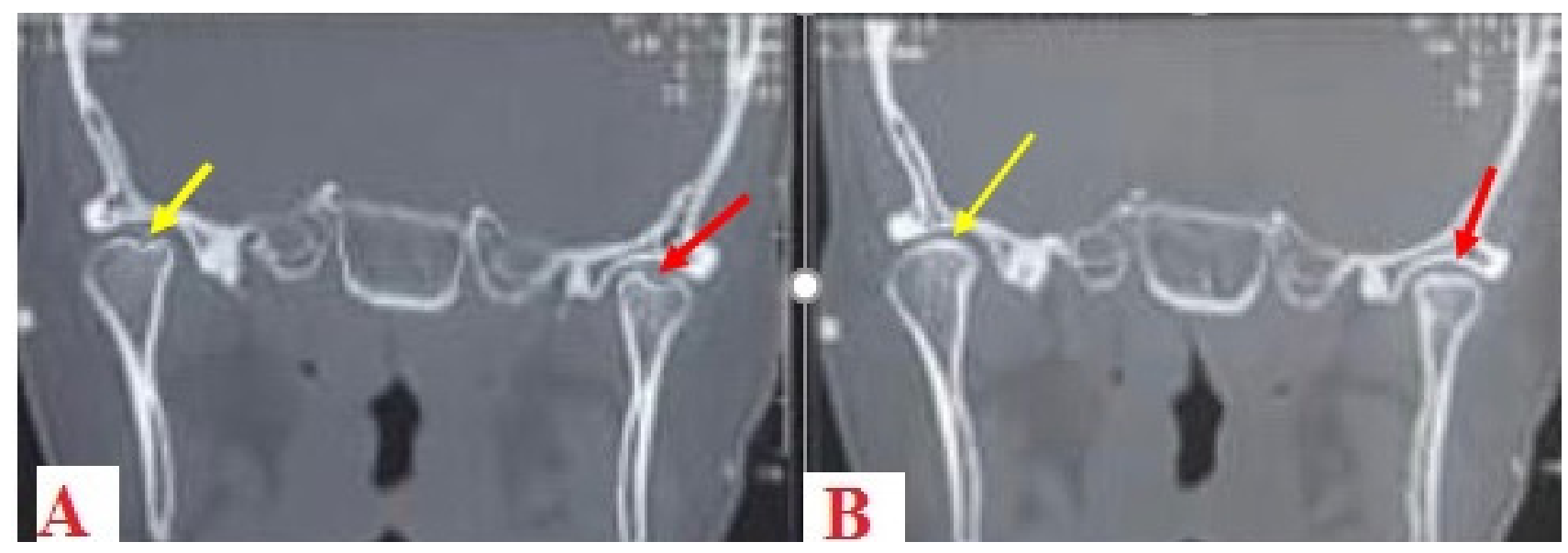

Figure 13: Group I CT (coronal view) A; preoperative CT showing osteophytes (red arrow) and erosion of condyles (yellow arrow)B; postoperative CT showing moderate reparative changes.

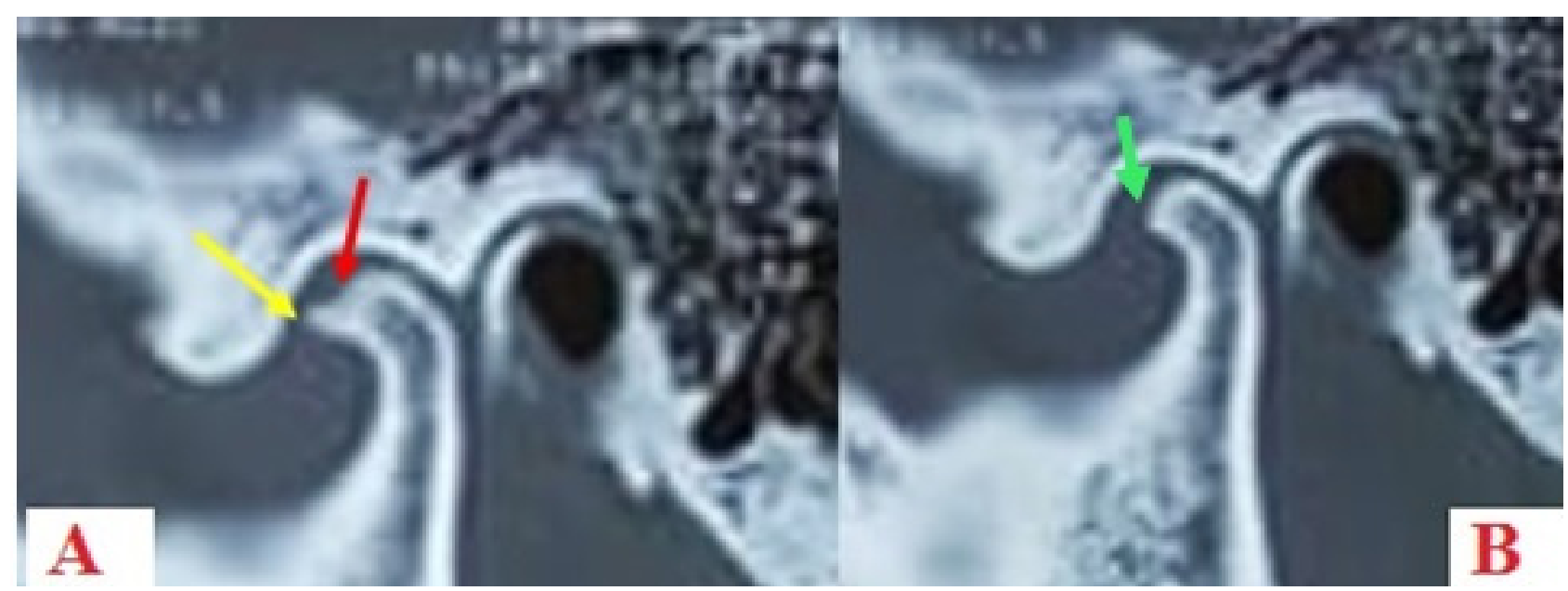

Figure 14: Group II CT (sagittal view) A:Preoperative CT showing narrowing of joint space, osteophytes(yellow arrow), erosions of condyle(red arrow) B: Postoperative CT showing moderate increase in joint space and reparative changes of erosions (green arrow).

\section{DISCUSSION}

The present study was conducted to compare and evaluate the effect of hyaluronic acid in opposition to adipose derived stem cells on TMJ osteoarthritis. It is worth mentioning that comparing the outcome of our present study to those perceived in previous researches, we were faced with the limited number of long term assessments for both treatment maneuvers. However, results attained in Group I were coherent with those of Kutuc, et $a l^{[28]}$ who in a comparative study evaluating the effect of platelet rich plasma, hyaluronic acid and steroids injections on tmj osteoarthritis. They demonstrated the moderate clinical effect of HA on TMJ osteoarthritis within a follow up period of 3months. Also, Bergstand, et al ${ }^{[13]}$ in 2019 conducted a similar study where the long-term outcome of arthrocentesis with and without HA on TMJ/ OA and reported the short-term efficiency of HA.

Gurung et al[29], in 2017 conducted a study comparing the effect of arthrocentesis alone and coupled with hyaluronic acid on $\mathrm{TMJ} / \mathrm{OA}$; results retrieved were in favor to the hyaluronic acid group. Unfortunately patients were followed up for only twelve weeks these results were similar to the initial improvement obtained in our present study. Likewise, Killic, et $a l^{[30]}$ in a similar study reported the beneficial effect of HA following arthrocentesis only on a short term basis.

In contrast, Nardini et $a^{[31]}$ gained different results in a 1 year follow up study on the effect of arthrocentesis and HA injection on patients suffering from TMJ/OA, marked improvement was reported by the study group and was maintained for 1 year. Likewise, Yakan and Toameh $^{[32]}$ reported long term efficiency of hyaluronic acid in alleviating pain and dysfunction related to TMJ osteoarthritis and their results were maintained for a period of 9 months. The variation of these results and those of our present study may be attributed to various factors, the most important of which is the repeated regimen. The arthrocentesis/injection procedure is repeated weekly 
for 3 - 5 consecutive weeks in contrast to our single technique. Yet, Hegab, et $a l^{[33]}$ in 2015 reported the short term effectiveness of HA on symptoms associated with $\mathrm{TMJ} / \mathrm{OA}$ inspite of repeating the technique for three consecutive weeks. Another factor having an impact on clinical results is the type of hyaluronic acid used regarding its molecular weight. In our present study, high molecular weight hyaluronic acid is used which is claimed by several studies to possess minimal therapeutic effect in comparison with its low molecular weight counterpart ${ }^{[34-35]}$.

As for Group II, results perceived in the present study supports the theory of pluripotency of mesenchymal stem cells and its ability to relief TMJ/OA symptoms and repair the existing degeneration within the joint cartilage and bone ${ }^{[36]}$. This was manifested by the marked rapid improvement within all parameters and they were sustained till the end of the follow up period of 18 months.

Comparing our obtained results to those of previous studies was challenging due to the scarcity of long-term assessments of ADCSCs on the TMJ/OA. However, ADSCs were proven a competent treatment maneuver for arthritis within the knee joint. This was manifested repeatedly by several other studies, Toghraie, et al ${ }^{[37]}$ in 2015 , conducted an experimental comparative study to assess the effect of intraarticular injection of ADSCs into induced osteoarthritis in rabbits knees. After 20 weeks after the injection, those joints injected with stem cells showed less cartilage degeneration, decreased osteophyte formation, and Subchondral sclerosis in addition to the superior quality of existing cartilage compared to the control group. Likewise, injection of Adipose derived stem cells in the osteoarthritic knees of humans also showed enhancement of cartilage regeneration and the subsiding of all related dysfunction ${ }^{[38-39]}$.

Moreover, Hong, et $a l^{[40]}$ in a study comparing the effect of hyaluronic acid versus adipose derived stem cells on knee joints demonstrated the superior results of ADSCs. Improvements were manifested both clinically and radiologically; results were maintained for 12 months. In contrast the control group (HA acid) didn't show any advancement and its results were the same as the baseline.

As for the TMJ/OA an experimental study conducted by Putnová et $a l^{[41]}$ where non differentiated human adipose derived stem cells were injected into induced temporomandibular joints of rabbits, results emphasized the ability of stem cells to enhance the reparative process within the condyles regardless of the inflammatory process initiated due to the allogeneic nature of the stem cells used.

Mahmood, et al ${ }^{[42]}$ in 2019 upon investigating the effect of injecting nano fats on the associated symptoms of $\mathrm{TMJ} / \mathrm{OA}$ acknowledged similar results to our present study. Authors reported resolving of all dysfunction related to the osteoarthritis, however the sample size of the study was very small and the follow up period wasn't clearly mentioned. Similarly in a research conducted by Carboni, et $a l^{[43]}$ studying the effect of adipose derived stem cells on temporomandibular disorders both clinically and radiologically, results concluded the efficacy of ADSCs in resolving all clinical symptoms associated with osteoarthritis, however obtained results are inconclusive owing to the very small sample size and relatively short follow up time of 6 months only.

TGF $\beta 1$ level within the synovial fluid was chosen as a marker for evaluating the progression of $\mathrm{TMJ} /$ $\mathrm{OA}$ in both treatment modalities. In our present study results obtained were congruent with those obtained by previous studies which also revealed the drop in TGF $\beta 1$ level[ $\left.{ }^{[44}-45\right]$. However Group II manifested a marked decline in concentration levels which strongly augment the efficiency of stem cells to abate the ongoing degenerative cascade in contrast to the hyaluronic acid.

Computerized tomography was the maneuver of choice for preoperative diagnosis and follow up of all patients. The choice was based on the recommendation of several studies manifesting its accuracy in detecting slight bony changes within the joint in addition to its ability to visualize both superior and medial surface of the condyle ${ }^{[46]}$. Comparing radiological findings obtained in our study to with those of previous researches, we were challenged by the scarcity of long term radiological assessments of both treatment maneuvers.

However, Similar results to those obtained in Group I were obtained by Møystad ${ }^{[47]}$ in a study comparing effects of arthrocentesis and hyaluronic acid versus steroids on tmj osteoarthritis, using CT scans. Six months Postoperative radiographs revealed that $75 \%$ of patients treated with hyaluronic acid faced no change or even got worse.

In 2011 an experimental study was carried on by Liu, et $a l^{[48]}$ where $\mathrm{TMJ} / \mathrm{OA}$ was induced in rabbits followed by treatment of three different modalities including hyaluronic acid, insulin growth factor or a combination of both, results using micro CT showed the poor regenerative effect of hyaluronic acid on osteoarthritic joints. Although this study didn't use arthrocentesis but it casts a shadow on the minimal potential of hyaluronic acid in treatment of TMJ/OA. Likewise, Gurung, et al[29] in 2017 obtained similar results where the mild reparative ability of hyaluronic acid on the osteoarthritic degeneration was manifested using CBCT .Similar results were attained by Sun, et $a l^{[49]}$ where the hyaluronate injection in the osteoarthritic joints improved the clinical symptoms but it failed to quit the progression of joint degeneration.

In contrast, Postoperative CTs of Group II showed significant reparative remodeling within the Temporomandibular joint which augments the role of stem cells in reversing the TMJ degenerative changes. These findings are similar to those of Chen, et al[50], who investigated the effect of chondrogenic differentiation of mesenchymal stem cells on TMJ induced osteoarthritis in rabbits using micro computed tomography. The collected 
results showed repair of bony degeneration in the study group suggesting the ability of in vitro differentiated mesenchymal cells to repair joint destruction.

Never the less In 2019 Kim et al ${ }^{[51]}$ obtained similar results using mesenchymal human umbilical cord stem cells on induced TMJ osteoarthritis in rabbits. Results gathered using micro computed tomography showed reversal of the preoperative bony degeneration within the condyles which appeared with a smooth and continuous contour.

Concerning our current study subcutaneous fat cells were chosen as a source of stem cells owing to their abundance, ease of access and simple harvest technique which is far less invasive and less painful in comparison to that of bone marrow ${ }^{[52]}$. Moreover, autologous fat cells are not associated with any ethical controversies unlike the embryonic stem cells ${ }^{[53]}$.

Results attained in our present study support those of previous researches where ADSCs demonstrated their ability to repair the damaged articular cartilage in osteoarthritic joints, through the production of cartilage matrix, reduction of the local inflammatory process thus reducing synovitis and maintaining a favorable environment for tissue regeneration ${ }^{[54-55]}$. These therapeutic potentials are attributed to several properties of ADSCs including; their ability to differentiate into chondrocytes , together with their marked paracrine effect which is manifested by secretion of bioactive molecules including anti-inflammatory and chondroprotective mediators ${ }^{[23}-$ 56]. Moreover, ADSCs exhibit immunomodulatory and antifibrotic properties thus protecting cells from oxidative stress and apoptosis ${ }^{[57]}$.

Results attained in the present study suggested the high potential and ability of adipose derived stem cells to reduce the dysfunction related to $\mathrm{TMJ} / \mathrm{OA}$ together with ceasing the osteoarthritic degenerative process permitting articular cartilage and bone repair.

Certain limitations were noticed in the present study, among them is choosing CT as the sole radiographic assessment. Although CT provides excellent details concerning the joint bone structures yet it provides no clue regarding disc position which is a prime factor in the initiation and progression of the disease. Thus, the fact that the position of the disc is not taken into consideration can affect the final outcome of the therapeutic procedure.

\section{CONFLICT OF INTEREST}

The authors declare no conflict of interest.

\section{CONCLUSION}

Adipose derived stem cells intraarticular injection is considered a safe and efficient method of treating $\mathrm{TMJ} / \mathrm{OA}$. However, assessment of the disc position should be provided. Also, larger study group for longer follow up period is recommended.

\section{REFERENCES}

1. Zarb GA, Carlsson GE: Temporomandibular disorders: osteoarthritis. J Orofac Pain 1999 Fall,13 (4): 295 - 306.

2. Tanaka E, Detamore MS, Mercuri LG. Degenerative disorders of the temporomandibular joint: etiology, diagnosis, and treatment. J Dent Res. 2008 Apr; 87 (4): 296 - 307.

3. Kilic SC, Kilic N, Sumbulu MA. Temporomandibular joint osteoarthritis: cone beam computed tomography findings, clinical features, and correlations. International Journal of Oral and Maxillofacial Surgery, 2015 October; 44 (10): Pages 1268 - 127.

4. Lei J, Han J, Liu M, Zhang Y, Yap AU, Fu KY. Degenerative temporomandibular joint changes associated with recent-onset disc displacement without reduction in adolescents and young adults. J Craniomaxillofac Surg. 2017 Mar; 45 (3): 408 - 413.

5. Wang $\mathrm{X}$ D, Zhang $\mathrm{YH}$, Gan $\mathrm{YH}$, Zhou $\mathrm{YH}$ .Current Understanding of Pathogenesis and Treatment of TMJ Osteoarthritis March 2015; 94 (5): 666 - 673.

6. Massilla M F, Sivasubramanian SS. A study of temporomandibular joint osteoarthritis using computed tomographic imaging. Biomed J. 2016 Jun; 39 (3): 201 - 6.

7. Akashi M, Hasegawa T, Takahashi S, Komori T. Four-Dimensional computed tomography evaluation of condylar movement in a Patient With Temporomandibular Joint Osteoarthritis. Journal of Oral and Maxillofacial Surgery. 2018 Feb; 76 (2): 304 - 313.

8. Da Costa GF, Souza RDC, de Araújo GM , Gurgel BCV , Barbosa GAS Calderon PDS. Does TGF- $\beta$ play a role in degenerative temporomandibular joint diseases? A systematic review. Cranio; 2017 Jul; 35 (4): 228 - 232.

9. Wiegertjes $\mathrm{R}$, van Caam $\mathrm{A}$, van Beuningen $\mathrm{H}$, Koenders M, van Lent P, van der Kraan P, van de Loo F, Davidson BE.TGF- $\beta$ dampens IL-6 signaling in articular chondrocytes by decreasing IL-6 receptor expression. Osteoarthritis and Cartilage. 2019 Aug; 27 (8): 1197 - 1207.

10. Mejersjo C, Wenneberg B. Diclofenac sodium and occlusal splint therapy in TMJ osteoarthritis: 
a randomized controlled trial. Journal of Oral rehabilitation.2008 Oct; 35 (10): 729 - 738.

11. Nicolakis P, Erdogmus B, Kollmitzer J, KerschanSchindl K, Sengstbratl M, Nuhr M, Crevenna, R, Fialka-Moser V. Long-term Outcome After Treatment of Temporomandibular Joint Osteoarthritis With Exercise and Manual Therapy. Cranio, 2002 Jan, 20 (1), 23 - 7.

12. Nitzan DW, Svidovsky J, Zini A, Zadik Y. Effect of Arthrocentesis on Symptomatic Osteoarthritis of the Temporomandibular Joint and Analysis of the Effect of Preoperative Clinical and Radiologic Features. Journal of Oral and Maxillofacial surgery. 2017 Feb; 75 (2): 260 - 267.

13. Bergstrand S ,Ingstad HK , Møystad A, Bjørnland $\mathrm{T}$. Long term effectiveness of arthrocentesis with and without hyaluronic acid injection for treatment of temporomandibular joint osteoarthritis. J Oral Sci. 2019 Mar 28; 61 (1): 82 - 88.

14. Ituriaga $\mathrm{V}$, Bornhardt $\mathrm{T}$, Manterola $\mathrm{C}$, Brebi P. Effect of hyaluronic acid on the regulation of inflammatory mediators in osteoarthritis of the temporomandibular joint: a systematic review. Int J Oral Maxillofac Surg. 2017 May; 46 (5): 590 - 595.

15. Han Y, Li X, Zhang Y, Han Y, Chang F, Ding J. Mesenchymal Stem Cells for Regenerative Medicine Cells. 2019 Aug; 8 (8): 886.

16. Nancarrow-Lei R, Mafi P, Mafi R, Khan W. A Systemic Review of Adult Mesenchymal Stem Cell Sources and their Multilineage Differentiation Potential Relevant to Musculoskeletal Tissue Repair and Regeneration. Curr Stem Cell Res Ther. 2017 June; 12 (8): 601 - 610.

17. Gimble JM: Adipose tissue-derived therapeutics. Expert Opin Biol Ther 2003 Aug; 3 (5): 705 - 13.

18. Kitagawa Y, Korobi M, Toriyama K, Kamei Y, Torii S: History of discovery of human adipose-derived stem cells and their clinical application. Jpn J Plast Reconstr Surg 2006 Oct; 49: 1097 - 1104.

19. Gimble JM, Zvonic S, Floyd ZE, Kassem M, Nuttall M. Playing with bone and fat. J Cell Biochem 2006 May 15; 98 (2): 251 - 66.

20. Bunnel BA, Flaat M, Gagliardi C, Patel B, Ripoll C. Adipose-derived Stem Cells: Isolation, Expansion and Differentiation Methods J2008 June; 45 (2): 115 - 12.
21. Estes BT, Diekman BO, Gimble JM, Guilak F. Isolation of adipose-derived stem cells and their induction to a chondrogenic phenotype. Nature Protocols. 2010 Jul; 5 (7): 1294 - 311.

22. Erickson GR, Gimble JM, Franklin DM, Rice HE, Awad H, Guilak F. Chondrogenic Potential of Adipose Tissue-Derived Stromal Cells in Vitro and in Vivo. Biochemical and Biophysical Research Communications. 2002 Jan; 290 (2): 763 - 769.

23. Huurne Mt, Schelbergen R, Blattes R, Blom A, Munter W, Grevers LC, Jeanson J, Noel D, Casteilla L, Jorgensen C, Van den Berg W, van Lent P L E M .Antiinflammatory and Chondroprotective Effects of Intraarticular Injection of Adipose-Derived Stem Cells in Experimental Osteoarthritis . Arthritis and Rheumatism 2012 Nov; 64 (11): 3604 - 3613.

24. Dworkin SF, LeResche L. Research diagnostic criteria for temporomandibular disorders: review, criteria, examinations and specifications, critique. J Craniomandib Disord. 1992 Fall; 6 (4): 301 - 55.

25. Klein JA. Tumescent technique for regional anaesthesia permits lidocaine doses of $35 \mathrm{mg} /$ $\mathrm{kg}$ for liposuction. J Dermatol Surg Oncol. 1990 March; 16 (3): $248-63$.

26. Tomiyama K, Murase N, Stolz DB, Toyokawa H, O'Donnell DR, Smith DM, Dudas JR, Rubin JP, Marra KG. Characterization of transplanted green fluorescent protein+ bone marrow cells into adipose tissue. Stem Cells 2008 Feb; 26 (2): 330 -338 .

27. Nitzan DW, Dolwick MF, Martinez GA. Temporomandibular joint arthrocentesis: a simplified treatment for severe, limited mouth opening. J Oral Maxillofac Surg. 1991 Nov; 49 (11): $1163-7$.

28. Kutuk SG, Gökçe G, Muhammet Arslan M, Özkan Y, Kütük M , Kursat OArikan K.Clinical and Radiological Comparison of Effects of Platelet-Rich Plasma, Hyaluronic Acid, and Corticosteroid Injections on Temporomandibular Joint Osteoarthritis. Journal of Craniofacial Surgery: 2019 June 30 (4): 1144 - 1148.

29. Gurung T, Singh RK, Mohammad S, Pal US, Mahdi AA, Kumar M .Efficacy of arthrocentesis versus arthrocentesis with sodium hyaluronic acid in temporomandibular joint osteoarthritis: A comparison. Natl J Maxillofac Surg. 2017 Jan-Jun; 8 (1): 41 - 49. 
30. Kilic SC, Güngörmüs M. Is arthrocentesis plus platelet-rich plasma superior to arthrocentesis plus hyaluronic acid for the treatment of temporomandibular joint osteoarthritis: a randomized clinical trial. Int $\mathrm{J}$ Oral Maxillofac Surg: 2016 June; 45, 1538 - 1544.

31. Guarda-Nardini L, Stifano M, Brombin C, Salmaso L, Manfredini D.A one-year case series of arthrocentesis with hyaluronic acid injections for temporomandibular joint osteoarthritis. Oral Surg Oral Med Oral Pathol Oral Radiol Endod. 2007 Jun; 103 (6): e14 - 22.

32. Yakan A, Toemah. Treatment of Temporomandibular Joint Osteoarthritis by Using Arthrocentesis and Hyaluronic Acid Injections: Modified Protocol. Journal of Dental Health, Oral Disorders and Therapy, 2014 Sep; 1 (5): 135 - 139.

33. Hegab AF, Ali HE, Elmasry M. Platelet-Rich Plasma Injection as an Effective Treatment for Temporomandibular Joint Osteoarthritis. Journal of Oral and Maxillofacial Surgery .2015 September; 73 (9): 1706 - 1713.

34. Kwiecinski JJ, Dorosz SG, Ludwig TE, Abubacker S, Cowman MK, Schmidt TA. The effect of molecular weight on hyaluronan's cartilage boundary lubricating ability alone and in combination with proteoglycan 4. Osteoarthritis Cartilage. 2011 Nov; 19 (11): 1356 - 62.

35. Wei L, Xiong H, Li B, Gong Z, Li J, Cai H. Change of HA molecular size and boundary lubrication in synovial fluid of patients with temporomandibular disorders. J Oral Rehabil. 2010 April; 37 (4): 271 - 7.
36. Song Y,Du H, Dai C, Zhang, L, Li S, Hunter D J, Lu L, Bao C. Human adipose-derived mesenchymal stem cells for osteoarthritis: A pilot study with long-term follow-up and repeated injections. Regen. Med.2018 April, 13 (3): 295 - 307.

37. Toghraie FS, Chenari N, Gholipour MA, Faghih Z, Torabinejad S, Dehghani S, Ghaderi A. Treatment of Osteoarthritis With Infrapatellar Fat Pad Derived Mesenchymal Stem Cells in Rabbit. Knee. 2011 May; 18 (2), 71 - 5.

38. Lu L, Dai c, Du H,Zhang Z, Du H, Li S, Ye P, Fu Q, Zhang Li, Wu X, Dong Y, Zhao D, Song Y, Zhao D, Pang Y. Treatment of knee osteoarthritis with intra-articular injection of autologous adipose-derived mesenchymal progenitor cells: a prospective, randomized, double-blind, activecontrolled, phase IIb clinical trial. Stem cell research and therapy. 2019 May, 10: 143.

39. Davatchi F, Sadeghi Abbdolla B, Mohyeddin M, Shahram F, Nikbin B. Mesenchymal stem cell therapy for knee osteoarthritis. Preliminary report of four patients. International Journal of Rheumatic diseases. 2011 May; 14 (2), 211 - 215.

40. Hong Z, Chen J, Zhang S, Zhao C,Bi M, Chen $\mathrm{X}, \mathrm{Bi} \mathrm{Q}$. Intra-articular injection of autologous adipose-derived stromal vascular fractions for knee osteoarthritis: a double-blind randomized self-controlled trial. International Orthopaedics 2019 May: 43 (5), 1123 - 1134.

41. Putnová B, Hurník P, Jekl V, Žiak D, Machoň V, Škorič M , Stránský J , Štembírek J. Effect of human adipose-derived regenerative cells on temporomandibular joint healing in 